\title{
Lumbar Epidural Cavernous Hemangioma : A Case Report
}

\author{
Kanuj Kumar Barman ${ }^{1}$, Akhlaque Hossain Khan ${ }^{2}$, Md. Tauhidur Rahman ${ }^{3}$, Bishnu Pada Dey ${ }^{4}$, Md. Jalal Uddin ${ }^{5}$
}

\begin{abstract}
A 34 year smale patient presented with diffuse low-back pain with bilateral radiculopathy for 8 months duration. The magnetic resonance imaging showed an extradural space occupying lesion in spinal canal from $L 2$ to L5 vertebral levels. The mass was well-marginated with bone involvement. Radiological diagnosis was questionable. The patient underwent L2 to L5 laminectomy under general anesthesia. Intraoperatively, the tumor was purely extradural in location with devoid of attachment to the nerves or dura. Total excision of the extradural compressing mass was not possible due to high vascularity. Histopathology revealed cavernous hemangioma. Purely epidural hemangiomas are uncommon and should be considered in the differential diagnosis of spinal epidural soft tissue masses. Findings that may help differentiate this lesion from the disk prolapse include more common meningiomas and nerve sheath tumors. Early diagnosis and complete removal is the treatment of choice.
\end{abstract}

Key Words: Lumbar, Epidural, Cavernous Hemangioma.

\section{INTRODUCTION:}

Extradural cavernous hemangiomas are very rare. In most cases, they arise from the vertebral bodies and extend into the extradural space. ${ }^{1,2,3}$ Purely extradural cavernous hemangiomas without any vertebral body involvement are extremely rare and account for only $4 \%$ of all extradural spinal tumors. ${ }^{3,4}$ They are most commonly located in the posterior aspect of the thoracic epidural space and

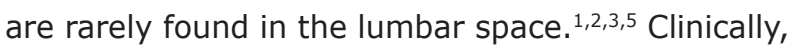
they can cause symptoms of radiculopathy, which causes misdiagnosis as herniated intervertebral disc disease. In the present study, we are presenting a rare case of a pure lumbar epidural cavernous hemangioma at the L4-5 level with its preoperative diagnosis and the outcome of surgical treatment.

\section{CASE REPORT:}

The patient was a 34 years male who had been suffering from low-back pain with radiation towards the lateral thigh down to great toe for the last 8 months and symptoms were exacerbated within the past 3 months. He had no weakness in either of the lower extremities. Upon neurological examination; tone, power, deep tendon reflexes of both lower extremities were normal and sphincter function was intact. The patient had no significant past medical history and the laboratory tests were within normal limits.

On Lumbosacral spine magnetic resonance imaging (MRI), a spiral epidural mass was seen as isointense on T1WI and hyperintense on T2WI with heterogeneous gadolinium-enhancement T1WI at

\section{Authors' information: \\ ${ }^{2}$ Dr. Kanuj Kumar Barman, Associate Professor, Department of Neurology, Bangabandhu Sheikh Mujib Medical University, Dhaka, Bangladesh}

${ }^{2}$ Prof. Dr. Akhlaque Hossain Khan, Department of Neurosurgery, Bangabandhu Sheikh Mujib Medical University, Dhaka, Bangladesh

${ }^{3}$ Dr. Md. Tauhidur Rahman, Resident, Departments of Neurosurgery, Bangabandhu Sheikh Mujib Medical University, Dhaka, Bangladesh

${ }^{4}$ Dr. Bishnu Pada Dey, Assistant Professor, Department of Pathology; Bangabandhu Sheikh Mujib Medical University, Dhaka, Bangladesh

${ }^{5}$ Prof. Dr. Md. Jalal Uddin, Department of Neurology, Mymensingh Medical College, Mymensingh, Bangladesh

Correspondence : Dr. Kanuj Kumar Barman, Phone: +880 1931646543, E-mail:kanuj_barman@yahoo.com 
the level of $L 2-5$. Additionally, posterior body $L 3,4$ showed significant contrast enhancement (Figure $1,2)$.
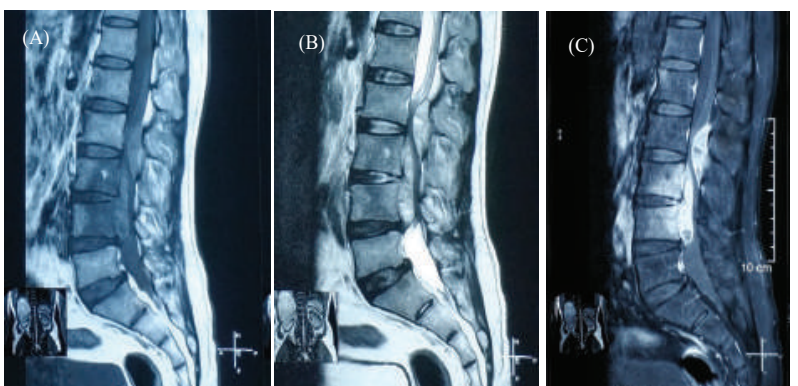

Figure 1 : MRI Sagittal view showing an epidural mass which was occupying post aspect of spinal cord at $L 2$, anterior aspect at $L 3,4$ level; seen as isointense on T1WI (A) and hyperintense on T2WI (B) and heterogeneous enhancement on post contrast film (C). More than half of the $L 3,4$ vertebral body had shown involvement by the lesion.

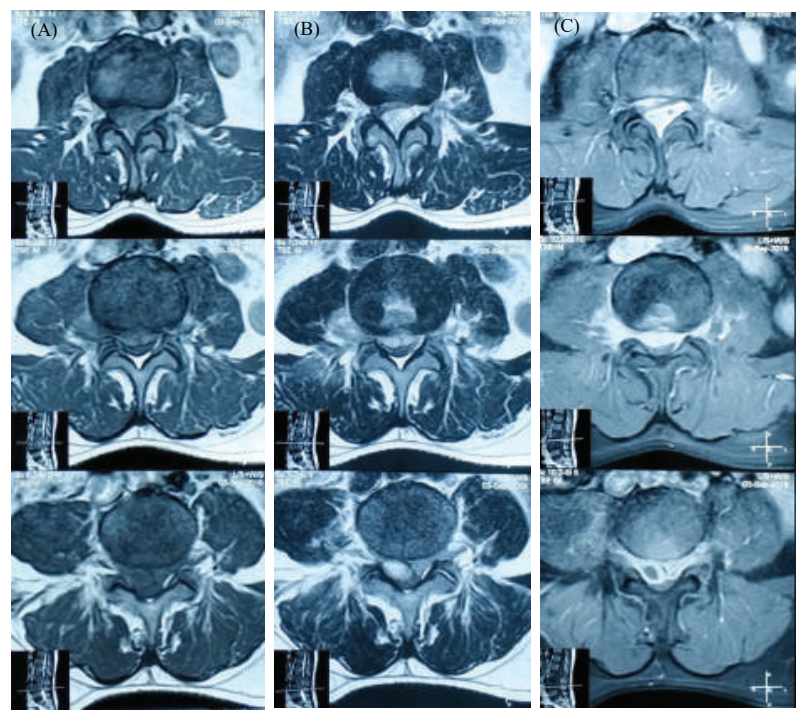

Figure 2 : MRI multiple axial view showing isointense on T1WI (A) and hyperintense on T2WI (B) and heterogeneous enhancement $(C)$ within the lesion.

Neural elements decompression was done by laminectomy $\mathrm{L}^{2,3,4}$ and a reddish brown mass with a soft consistency was found while the thecal sac was retracted. It was highly vascular and significant bleeding occurred during the operation. The mass was removed partially and hemostasis was achieved. Neurological deterioration did not occur during the postoperative period.

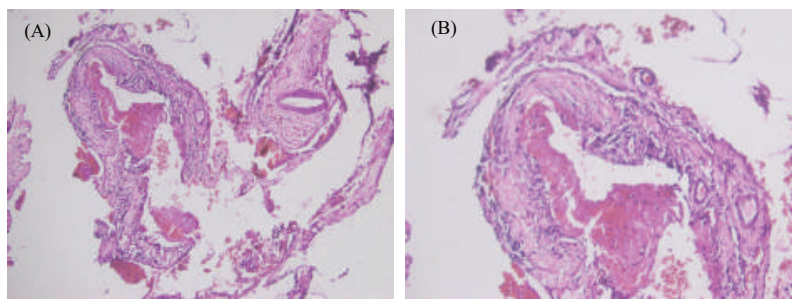

Figure 3: Histopathology showed cavernous hemangioma. (A) $\times 4$ and (B) $\times 10$ showing large dilated vascular spaces containing blood, lined by a single layer of endothelium.

\section{HISTOPATHOLOGY}

Histopathology revealed cavernous hemangioma (Fig.3). Multiple dilated and ectatic vascular channels were found on histology which were closely spaced and contained blood. A single layer of benign endothelial cell lines the spaces. Nuclear pleomorphism and mitotic figures were not seen.

\section{DISCUSSION}

Cavernous hemangiomas may be found in multiple systems of the body. ${ }^{6}$ However, spinal cavernous hemangiomas are relatively rare with majority originates from the vertebral body and extends into the epidural space. A pure spinal epidural cavernous hemangioma is rare and was first reported in 1929 by Globus and Doshay. ${ }^{7}$

Cavernous hemangiomas are hematomas composed of small capillaries covered with a single layer of endothelium, characterized by lobules, separated by fibrous connective tissue septa and composed of irregular and dilated vascular channels. ${ }^{2,10}$ Clinical symptoms are caused by the mass effect, vascular movements, hemorrhage, thrombosis, cysts or cavern formation.

Surgical resection is the sole cure if the final diagnosis is a spinal cavernous hemangioma. But it is very difficult to diagnose before surgery. A study by Tekkoket al. ${ }^{11}$ reported on 14 surgical resections of cavernous hemangioma, none of which was diagnosed preoperatively. 
MRI is the most useful method to diagnose a cavernous hemangioma and differentiate from other diseases like intervertebral disc herniation, schwannoma, neurofibroma, angiolipoma, osteochondroma, synovial cyst, Iymphoma, chordoma and Ewing's sarcoma. For example, intervertebral disc herniation may present with none or peripheral enhancement and schwannoma may present less enhanced or neural foraminal widening; whereas lymphoma presents as isointenseon T2WI. In the case of angiolipoma, hyperintensity on T1WI can be observed owing to its high fat content. ${ }^{8,9,12-15}$

Surgical excision is recommended as early as possible because cavernous hemangiomas have a tendency to bleed and grow ${ }^{9}$. Massive bleeding can occur during the operation due to their hyper vascularity. En-bloc resection after coagulation is preferred. ${ }^{4,6,14}$ In cases of incomplete resection, radiation therapy has been suggested to control the tumor growth. Sohn et al. suggested performing stereotactic radiotherapy (32 Gy in 4 fractions). ${ }^{16}$

\section{CONCLUSION}

Pure spinal epidural cavernous hemangioma is very rare. The symptoms of radiculopathy due to this problem are similar with those of intervertebral disc herniation and it is difficult to make diagnosis preoperatively. MRI is an important diagnostic tool which can differentiate it from other diseases, and early surgical treatment is of utmost significance.

\section{REFERENCES}

1. Khalatbari MR, Abbassioun K, Amirjmshidi A: Solitary spinal epidural cavernous angioma: report of nine surgically treatedcases and review of the literature. Eur Spine J 2013;22:542-47.

2. Petridis AK, Doukas A, Hugo HH, Barth H, Mehdorn HM: A rare case of extradural lumbar nerve root cavernoma. Eur Spine J 2011;20(Suppl2):S348-S349.

3. Yunoki M, Suzuki K, Uneda A, Yoshino K: A case of dumbbellshapedepidural cavernous angioma in the lumbar spine. Surg Neurol Int 2015;6(Suppl10):S309-S312.

4. Sağlam D, Sari A, Cansu A: Spinal epidural cavernous hemangioma:a rare site of involvement. Spine J 2016; 16:e251.
5. Li TY, Xu YL, Yang J, Wang J, Wang GH: Primary spinal epiduralcavernous hemangioma: clinical features and surgical outcomein 14 cases. J Neurosurg Spine 2015; 22:39-46.

6. Feng J, Xu YK, Li L, Yang RM, Ye XH, Zhang N, et al: MRI diagnosis and preoperative evaluation for pure epidural cavernoushemangiomas. Neuroradiology 2009;51:741- 47.

7. Lim WJ, Hur JW, Ahn SY, Rhee JJ, Lee JW, Lee HK. Pure Spinal Epidural Cavernous Hemangioma: A Case Report. The Nerve $2016 ; 2(2): 87-9$.

8. Hemalatha AL, Ravikumar T, Chamarthy NP, Puri K: A pureepidural spinal cavernous hemangioma - with an innocuous facebut a perilous behaviour! J Clin Diagn Res 2013;7:1434-35.

9. Yaldiz C, Asil K, Ceylan D, Erdem S: Thoracic extraosseousepidural cavernous hemangioma. J Korean Neurosurg Soc 2015;57:65-67.

10. Ozkal B, Yaldiz C, Yaman O, Ozdemir N, Dalbayrak S: Extraosseous,epidural cavernous hemangioma with back pain. Pol J Radiol 2015;80:206-09.

11. Tekkök IH, Akpinar G, Güngen Y: Extradural lumbosacralcavernous hemangioma. Eur Spine J 2004;13:469-73.

12. Bayri Y, Ekşi MŞ, YalçınkayaKoç D, Konya D: Spinal epiduralcavernous angioma: two case reports and review of the literature. Acta Orthop Traumatol Turc 2015;49: 459-64.

13. Jang D, Kim C, Lee SJ, Ryu YJ, Kim J: Pure spinal epiduralcavernous hemangioma with intralesional hemorrhage: a rarecause of thoracic myelopathy. Korean J Spine 2014;11:85-88.

14. Rodríguez-Boto G, Rivero-Garvía M, Gutiérrez-González R,Pérez-Zamarrón A, Vaquero J: Spinal epidural cavernous angiomas. Neurologia 2014;29:443-45.

15. Shivaprasad S, Shroff G, Campbell GA: Thoracic epidural cavernoushemangioma imaging and pathology. JAMA Neurol 2013;70:1196-97.

16. Talacchi A, Spinnato $S$, Alessandrini F, Iuzzolino $P$, BricoloA: Radiologic and surgical aspects of pure spinal epiduralcavernous angiomas. Report on 5 cases and review of theliterature. Surg Neurol 1999;52:198-203. 